\title{
Human-centered design of a personal health record system for metabolic syndrome management based on the ISO 924I-210:2010 standard
}

This article was published in the following Dove Press journal: Journal of Multidisciplinary Healthcare

\section{Charic D Farinango' \\ Juan S Benavides' \\ Jesús D Cerón' \\ Diego M López' \\ Rosa E Álvarez ${ }^{2}$}

'Telematics Engineering Research Group, Faculty of Electronics and Telecommunications Engineering, Universidad del Cauca, Popayán, Colombia; ${ }^{2 H}$ uman Genetics Research Group, Faculty of Health Sciences, Universidad del Cauca, Popayán, Colombia
Correspondence: Diego M López Universidad del Cauca, Calle 5 4-70, Popayán 19002, Colombia

Tel +573015819362

Fax +578209813

Emaildmlopez@unicauca.edu.co
Background: Previous studies have demonstrated the effectiveness of information and communication technologies to support healthy lifestyle interventions. In particular, personal health record systems (PHR-Ss) empower self-care, essential to support lifestyle changes. Approaches such as the user-centered design (UCD), which is already a standard within the software industry (ISO 9241-210:2010), provide specifications and guidelines to guarantee user acceptance and quality of eHealth systems. However, no single PHR-S for metabolic syndrome (MS) developed following the recommendations of the ISO 9241-210:2010 specification has been found in the literature. Objective: The aim of this study was to describe the development of a PHR-S for the management of MS according to the principles and recommendations of the ISO 9241-210 standard.

Methods: The proposed PHR-S was developed using a formal software development process which, in addition to the traditional activities of any software process, included the principles and recommendations of the ISO 9241-210 standard. To gather user information, a survey sample of 1,187 individuals, eight interviews, and a focus group with seven people were performed. Throughout five iterations, three prototypes were built. Potential users of each system evaluated each prototype. The quality attributes of efficiency, effectiveness, and user satisfaction were assessed using metrics defined in the ISO/IEC 25022 standard.

Results: The following results were obtained: 1) a technology profile from 1,187 individuals at risk for MS from the city of Popayan, Colombia, identifying that $75.2 \%$ of the people use the Internet and 51\% had a smartphone; 2) a PHR-S to manage MS developed (the PHR-S has the following five main functionalities: record the five MS risk factors, share these measures with health care professionals, and three educational modules on nutrition, stress management, and a physical activity); and 3) usability tests on each prototype obtaining the following results: $100 \%$ effectiveness, $100 \%$ efficiency, and 84.2 points in the system usability scale.

Conclusion: The software development methodology used was based on the ISO 9241-210 standard, which allowed the development team to maintain a focus on user's needs and requirements throughout the project, which resulted in an increased satisfaction and acceptance of the system. Additionally, the establishment of a multidisciplinary team allowed the application of considerations not only from the disciplines of software engineering and health sciences but also from other disciplines such as graphical design and media communication. Finally, usability testing allowed the observation of flaws in the designs, which helped to improve the solution.

Keywords: human-centered design, ISO 9241-210, software development process, personal health record system, usability evaluation 


\section{Introduction}

The World Health Organization stated that cardiovascular diseases (CVDs) were the major cause of death in the last decade. ${ }^{1}$ Seventeen-and-a-half million people died from CVDs in 2012, representing $31 \%$ of all global deaths. Of these deaths, an estimated 7.4 million were due to coronary heart disease and 6.7 million were due to stroke. ${ }^{2}$ Projections $^{3}$ conclude that deaths from CVDs will rise to 23.3 million in 2030.

On the other hand, the International Diabetes Federation (IDF) reported that each year, 3.2 million people around the world died from complications associated with diabetes, where type 2 diabetes accounts for $90 \%$ of these deaths. ${ }^{4}$ Type 2 diabetes has also become one of the major causes of premature illness and death. ${ }^{4}$

Considering the relationship between CVDs and type 2 diabetes, the IDF and the cardiovascular community joined efforts in the study of common risk factors, accomplishing the definition of a new clinical entity named metabolic syndrome (MS). ${ }^{5} \mathrm{MS}$ is defined as a group of medical disorders that increase the risk of developing CVD and diabetes. ${ }^{6} \mathrm{An}$ estimated $20-25 \%$ of the world's adults suffer MS, and they are twice as likely to die from a heart attack or a stroke. Also, they are three times as likely to suffer these cardiac problems compared to people without the syndrome. In addition, people with MS are five times more likely to develop type 2 diabetes. ${ }^{4}$

Previous studies have shown that the adoption of healthy lifestyles is an effective intervention to prevent both diabetes and obesity in adults at high risk, ${ }^{7}$ especially by improving nutrition and increasing physical activity. ${ }^{8} \mathrm{MS}$ is reversible, so in addition to patient empowerment for self-care, it is important that health professionals support behavioral changes in their patients.

Information and communication technologies (ICT) have the potential to provide great support in the treatment of MS. For example, Fjeldsoe et $\mathrm{al}^{9}$ evaluated 10 interventions via short text messages (SMSs) for the clinical care of diabetes. However, according to Park and Kim, ${ }^{10}$ there are few studies measuring the effectiveness of web and mobile interventions in patients with hypertension or diabetes. Around MS, some applications have been developed that allow monitoring, reporting, and advising patients. However, few studies provide empirical research on the management of MS through Internet-based platforms. ${ }^{11}$ The main purpose of existing applications is to support changes in people's lifestyles, ${ }^{11,12}$ especially using web and mobile applications, ${ }^{10}$ but not directly focused on MS.
ICT tools have been proven to play an important role in the management of chronic diseases. For this reason, innovative technologies such as personal health record systems (PHR-Ss) take on greater importance and are becoming increasingly accepted. ${ }^{13,14}$ A PHR-S is a system for managing personal health records (PHRs) that offers a wide variety of features such as the capability to view or introduce personal health data, exchange secure messages with health care providers, schedule appointments, or support clinical decisions (eg, drug interaction alerts or reminders). The importance of a PHR-S is the possibility offered to individuals to access their medical records, perform self-management of diseases, and provide new ways of communication with health care providers. ${ }^{15}$ They are also platforms for action, which provide guidance, decision-making procedures, and creative display of information to translate the stored data into viable recommendations. ${ }^{16}$

Usability of a system is of great importance as it directly influences system-user acceptance. Frequently, user preferences are ignored, causing loss of interest, abandonment of the system, and possible additional redesign costs. Especially in health systems, user's adherence is essential for proper management of health problems; otherwise, the effectiveness of interventions is reduced and may compromise an individual's health. The user-centered design (UCD) is an approach for interactive systems development that focuses on providing good user experience. It aims to guarantee the effectiveness and efficiency of information technology (IT) systems, so the user can interact with the system with a high degree of satisfaction and success. ${ }^{17,18}$ Due to the demonstrated benefits of using standard software development methodologies, especially within the software industry, the human-centered design for interactive systems' (ISO 9241-210:2010) standard was first published in 2010 and recently reviewed. ${ }^{18}$ This international standard provides an overview of the requirements and principles of UCD.

From the perspective of a software engineering project, it is not enough to declare the UCD principles in the development process; it is necessary to adopt techniques and activities, and define concrete UCD work products in order to guarantee that the system design meets the needs, skills, and objectives of the user. ${ }^{19}$ However, the ISO 9241-210:2010 standard does not provide a detailed description of the methods and techniques needed to carry out a UCD, or guidance on how to integrate them into the development processes traditionally used by software development teams. For this reason, this study adopts an existing software development process called OpenUP/ISO Usability Maturity Model 
(MMU-ISO) $)^{20}$ and adjusts its elements to satisfy the ISO 9241-210 recommendations.

For our knowledge, up to date, there is no traditional software development process that includes the requirements and recommendations of ISO 9241-210 standard in its definition. Thus, there are no works describing the development process of a PHR-S that takes into consideration of the aforementioned standard. Therefore, the aim of this study is to describe the development of a PHR-S for the management of MS according to the principles and recommendations of the ISO 9241-210 standard for human-centered design of interactive systems.

\section{Methods}

The PHR-S presented in this study was developed within the context of the SIMETIC project, an experimental study in Colombia on the impact of three ICT (web portal, as social network, and a PHR) on the management of MS. ${ }^{20}$ The ethics committee at the Universidad del Cauca in Colombia approved the study (Act 6-1.25/7 of May 29, 2012). Written informed consent was obtained from all individual participants included in the study. The PHR-S was developed using the OpenUP/MMU-ISO software development process ${ }^{21}$ updated according to the activities and recommendations of the ISO 9241-210 standard. The updated process is called OpenUP/MMU-ISO 9241-210. ${ }^{22}$ OpenUP/MMU-ISO 9241 210 is a software development process based on OpenUP/ Basic, which integrates to its phases of development (inception, elaboration, construction, and transition), the four main UCD activities specified in the ISO 9241-210 standard: understand and specify the context of use, specify the user requirements, produce design solutions to meet user requirements, and evaluate the designs against requirements. In this way, it ensures that the project's software development team uses the UCD for the design and development of the solution. The process includes a specialized practice for the UCD that contains the definition of tasks, including recommendations and requirements established in the ISO 9241-210 standard. The UCD methodology puts a special emphasis on the multidisciplinary design and implementation of IT solutions. Medical recommendations regarding the structure and information in different stages of the process were obtained directly from specialist of the health care team: a nurse, a psychologist, a medical doctor, a nutritionist, and a doctor in physical activity sciences. Thus, the project had specialist for each section, who established nutrition, exercise, and stress management guides. In addition, the engineer's team and the health team were in constant face-to-face communication, which allowed discussing the kind of information and the way it should be presented.

In the next subsections, the tasks related to the UCD approach are described. A more detailed description of the process can be found in Farinango and Benavides. ${ }^{23}$

\section{Stage I: inception phase}

This phase aims to understand the extent of the problem and the feasibility of the proposed solution. For this, the software development activities included support for understanding the problem, eliciting the requirements, and defining the initial system architecture. In this phase, one iteration was conducted, consisting of the following UCD activities: understand and specify the context of use, specify the user requirements, and produce design solutions to meet user requirements.

\section{User information gathering: surveys}

To perform the activities understand and specify the context of use and specify the user requirements, it was necessary to apply methods for gathering information directly from users. Thus, a survey was conducted to gather data using a previously defined questionnaire with open-ended and closed-ended questions. This was a descriptive survey administered by members of the project research team for 4 months. The sample consisted of 1,187 individuals at risk of MS who were active workers from public and private companies in the city of Popayan, Colombia, between the ages of 18 and 65 years.

The purpose of the survey was to obtain personal information about the individuals' education and occupation; anthropometric, clinical, and preclinical data; lifestyle; and technology use. The information collected was used to define the context of use, the characterization of users, and their initial requirements.

\section{Stage 2: elaboration phase}

The purpose of this phase was to better understand the requirements and to create and establish a baseline for the system's architecture. However, considering that the UCD approach aims to execute early validations with users, it was decided to design an initial prototype of the system. Therefore, this phase had one iteration consisting of the following UCD's activities: specify the user requirements, produce design solutions to meet user requirements, and evaluate the designs against requirements. 


\section{User information gathering: focus group}

Based on the iterative nature of the UCD, more information directly collected from the users was needed. To do so, a focus group with users was performed. In this activity, users told their experiences and expectations, so it was possible to understand their attitudes, beliefs, desires, and reactions. The process prior to the implementation of the focus group consisted of the following two steps:

1. Development of a first mock-up of the PHR-S: the aim of this first step was to acquaint with existing PHR-S, by inspecting existing systems. One example is the Heart360 system, developed by the American Heart Organization. ${ }^{24}$ Following, the Balsamiq modeling tool was used to create wireframes, so a visually structure of the solution was obtained.

2. Implementation of the pilot focus group: it was performed with people (not users of the system) with the objective to validate the focus group protocol. There were eight people present and the following three moderators: a leading software development engineer, a health care professional, and a social communicator. At the end of the session, a discussion was held in which participants gave their opinions and feedback on the pilot.

To implement the focus group, seven MS patients were recruited. It was conducted in a large meeting room where all participants were sitting around the table so they could interact with each other. The protocol was the same as the pilot: each participant presented himself/herself, saying their name, occupation, and motivation to participate. Later, randomized subgroups were formed, promoting interaction and discussion. Then, questions were made about reading preferences between digital and printed format. Following, the definition of PHR and explanation of the system mock-up were presented. Participants were asked about the type of information (weight, waist circumference, physical activity, nutrition, etc.) they consider useful to include in the PHR along with recommendations and opinions about the system design.

\section{User information gathering: interviews}

In order to collect more information about users, individual interviews were conducted as a complement to the focus group. A total of eight people participated in the interviews. It was performed in a private room in which privacy was guaranteed and distractions were avoided. The same questions from the focus group were raised, using the same order and focus. In addition, new questions to explore other users' thoughts were included.

\section{Interdisciplinary design: brainstorming}

Once the team had collected enough information about the design of the application, a meeting with all team members was conducted in order to improve the initial design. The session was attended by

- a social media communicator,

- the project manager (a biologist, part of the health care team),

- a nurse (part of the health care team),

- a graphical designer,

- a leading software development engineer,

- two software developers.

The first step was to explain the goal of the session: to give opinions and ideas, considering the field of expertise of each member, so new designs could arise by taking into account the initially proposed designs and the information obtained so far. To do so, the health care team (biologist and nurse) has already determined to follow the IDF guidelines for the MS. As a result, the MS parameters section, where the risk factors are shown, was well defined. In this way, the interdisciplinary design had a starting point with already verified health care requirements.

After suggestions and requirements from users were gathered, sheets of paper were distributed. The objective was that participants draw how they believe the information should be structured and how the user interfaces should be. After a few minutes, each participant showed and explained their design to the other members. From the different mock-ups, the final designs were selected.

Figure 1 shows the first design of the PHR-Ss' home page.

\section{Stage 3: construction phase}

One of the main results in the construction phase was the system's architectural design. Architectural decisions are derived from the system's requirements obtained in the previous phases. In this phase, two iterations were performed, which include the following UCD activities: specify the user requirements, produce design solutions to meet user requirements, and evaluate the designs against requirements.

\section{Interdisciplinary design}

Within this phase, the prototypes were more elaborated and the members worked close together; especially the 


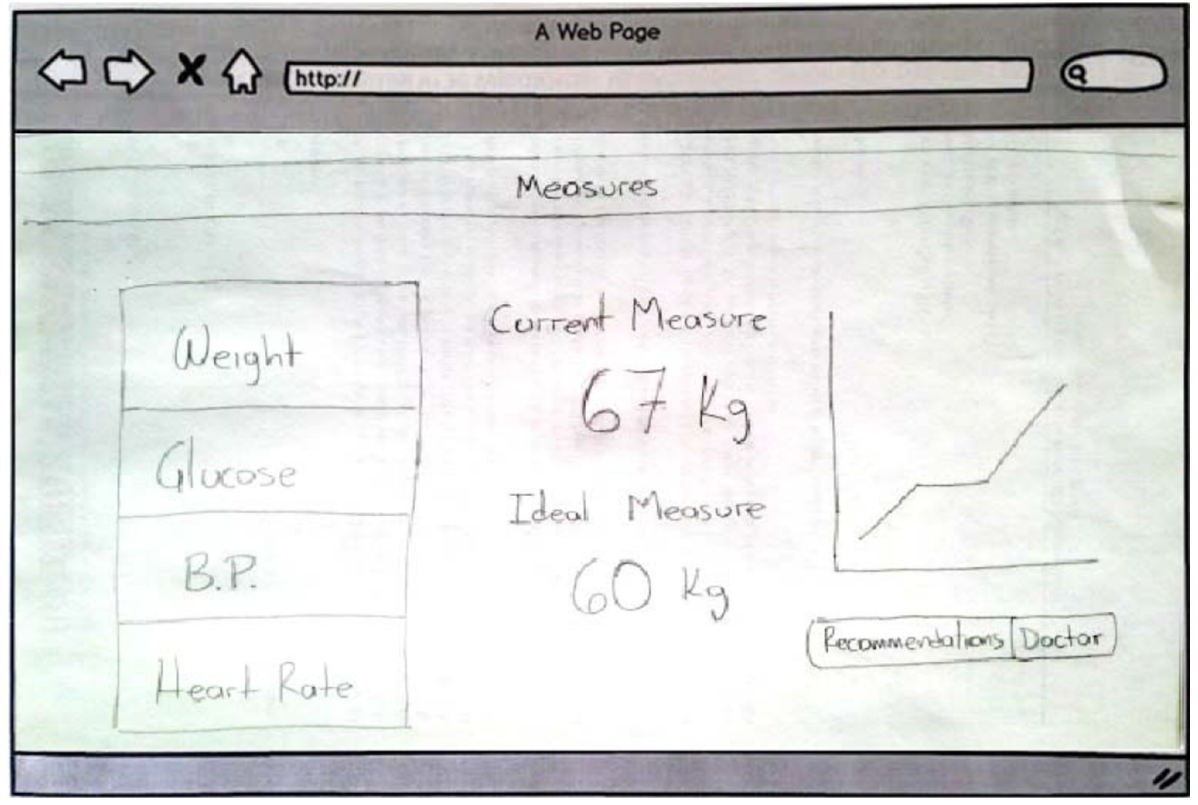

Figure I Home page mock-up drawn on a sheet of paper.

engineering team and the health care team were in constant communication, which allowed supporting the decisions, discussing the content of the system, and creating the medical requirements. There are three main subjects that need to be addressed to change a lifestyle: nutrition, physical exercise, and stress management. Therefore, the health care team added specialists for each area: a psychologist, a medical doctor, a nutritionist, and a doctor in physical activity science. These specialists elaborated the information guides for each section and the way it should be presented (videos, infographics, and text, among others)

From the user requirements and the understanding of the context of use, the tasks and subtasks that the system must perform to meet the user's goals were identified. These tasks were classified into those performed by the system and those performed by the users. This classification is based on an understanding of the interaction that the system will have with the user. Later, it was necessary to identify the interaction points, in order to define dialog techniques to structure the interaction. The next step was to design the dynamics of the interaction through activity diagrams, which allow the definition of sequences within the system and the information architecture. This allowed conducting the analysis, organizing and structuring of information, as well as selecting and presenting of data in the system. The techniques used to perform the above activities were storyboards and tasks models via Concur Task Trees method. Finally, the user interfaces were designed, and the functionality was coded and integrated using traditional software engineering modeling techniques such as use cases, sequence, class, component, and implementation models.

\section{Evaluation: usability test}

During the elaboration and construction phases, evaluations with potential users of the system were conducted in order to validate the resulting designs. The first step was to plan the evaluation, where evaluation goals were established. Usability metrics (efficiency, effectiveness, and user satisfaction) were defined based on the ISO/IEC 25022 Systems and Software Quality Requirements and Evaluation (SQUARE) - Measurement of quality-in-use standard. ${ }^{25}$ Then, the Think Aloud technique was established as the main technique for the usability testing, which is widely used and specified by the Department of Health and Human Services of the United States. ${ }^{26}$ It is used to understand the mind-set of the participants as they interact with a product, while making them express their thoughts aloud as they work. Along with this technique, a series of questions asked at the end of the test were made, in order to get more information about user experience. Finally, the tasks that users must perform during the test were defined.

The usability test was conducted with people at risk of having MS and was conducted in their workplace. The test protocol is summarized as follows: first, the research project was explained, along with details of the Think Aloud technique. During the evaluation, the face and the screen of the participant were recorded for later analysis. After the test, participants must answer the system usability scale (SUS) 
questionnaire, ${ }^{27}$ which contains 10 items, each one with a Likert scale of 1-5. This tool has become a standard of the industry with $>1,300$ references in papers or publications. ${ }^{27}$ Finally, effectiveness, efficiency, and user satisfaction were analyzed from the videos and SUS data.

\section{Stage 4: transition phase}

The objective of this phase was the refinement of the solution and the creation of tools for user support. It was not needed to perform more tests with users in this phase because the goals and objectives established in the project design were met and stakeholders agreed with the implemented solution. After a series of refinements, the development of the system was completed. This was done by taking into account user information collected by reconnaissance activities (first iteration) and validation activities (evaluations). Unlike previous phases, requirements of management activities were not carried out at this stage because neither the requirements nor usability goals changed. The transition phase also included the deployment discipline. Deployment is out of the scope of this project; nevertheless, this stage included user manuals written for future use.

\section{Results}

In this section, main work products resulting from each of the following four main activities of the UCD are detailed: understand and specify the context of use, specify the user requirements, produce design solutions to meet user requirements, and evaluate the designs against requirements.

\section{Understand and specify the context of use}

The context of use was defined from the surveys; focus group and interviews were conducted with people at risk of MS from the city of Popayan, Colombia.

Frequency of use of Internet is presented in Figure 2: $73 \%$ of people use Internet every day, with usage being more frequent in people younger than 30 years $(91.5 \%)$.

The survey also inquired about user preferences of different ICT interventions and use of other technology. The questions and results are listed in Table 1.

Among the strategies proposed, the more preferred one by users was to record personal health data, which had an acceptance rate of $67.9 \%$; this strategy is related to the use of a PHR-S. The least-accepted strategy was the exchange of health Information with others via Internet with an acceptance of $31 \%$, option related to social media strategies.

It was also analyzed the acceptance of the aforementioned ICT strategies in people with MS versus their age.

For example, the PHR strategy was more accepted by people who use Internet, have MS, and are between 40 and 49 years $(84.3 \%$ of people). The complete results are analyzed in Figure 3.

The results of the surveys were complemented with interviews and the focus group, obtaining the context of use, which is summarized as follows:

- Users are individuals aged between 30 and 59 years, mixed ethnicity, occupationally active, married or living
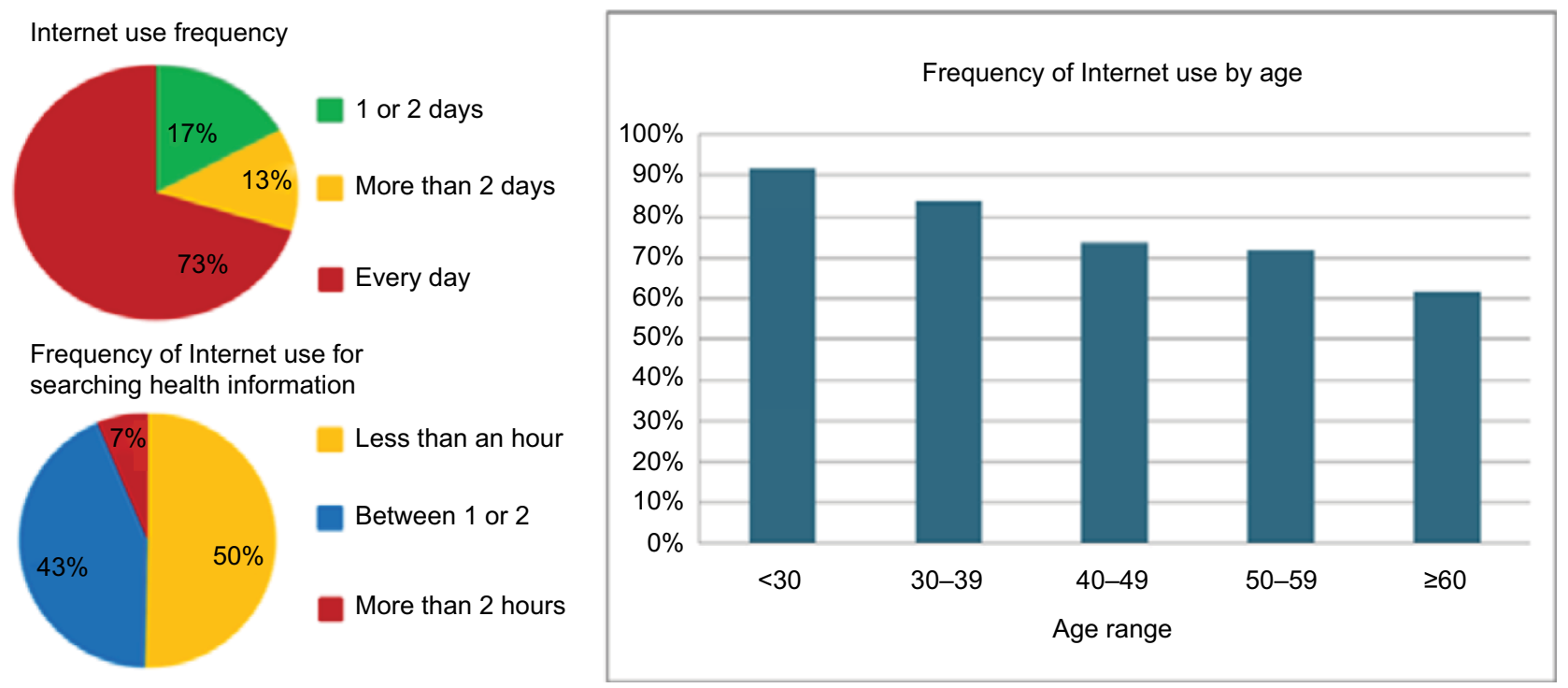

Figure 2 Technology profile describing the frequency (per week) of Internet use, Internet use for searching health information, and Internet use by age range of the participants. 
Table I Summary of responses regarding ICT strategies and technologies

\begin{tabular}{|c|c|c|c|c|}
\hline \multirow[t]{2}{*}{ Strategy } & \multicolumn{4}{|c|}{ Respondents } \\
\hline & Yes (n) & Yes (\%) & No (n) & No (\%) \\
\hline Agree to use ICT as a health care intervention & 935 & 78.8 & 251 & 21.1 \\
\hline Agree to exchange health Information with others via Internet & 368 & 31.0 & 819 & 69.0 \\
\hline Agree to receive news or readings via Internet & 543 & 45.7 & 644 & 54.3 \\
\hline Agree to receive videos via Internet & 569 & 47.9 & 618 & 52.1 \\
\hline Agree to receive personalized medical advice via Internet & 763 & 64.3 & 424 & 35.7 \\
\hline Agree to record personal health data & 806 & 67.9 & 381 & 32.1 \\
\hline Frequency of cellphone use & 1,162 & 97.9 & 25 & 2.1 \\
\hline Frequency of smartphone use & 605 & 51.0 & 582 & 49.0 \\
\hline
\end{tabular}

Abbreviation: ICT, information and communication technologies.

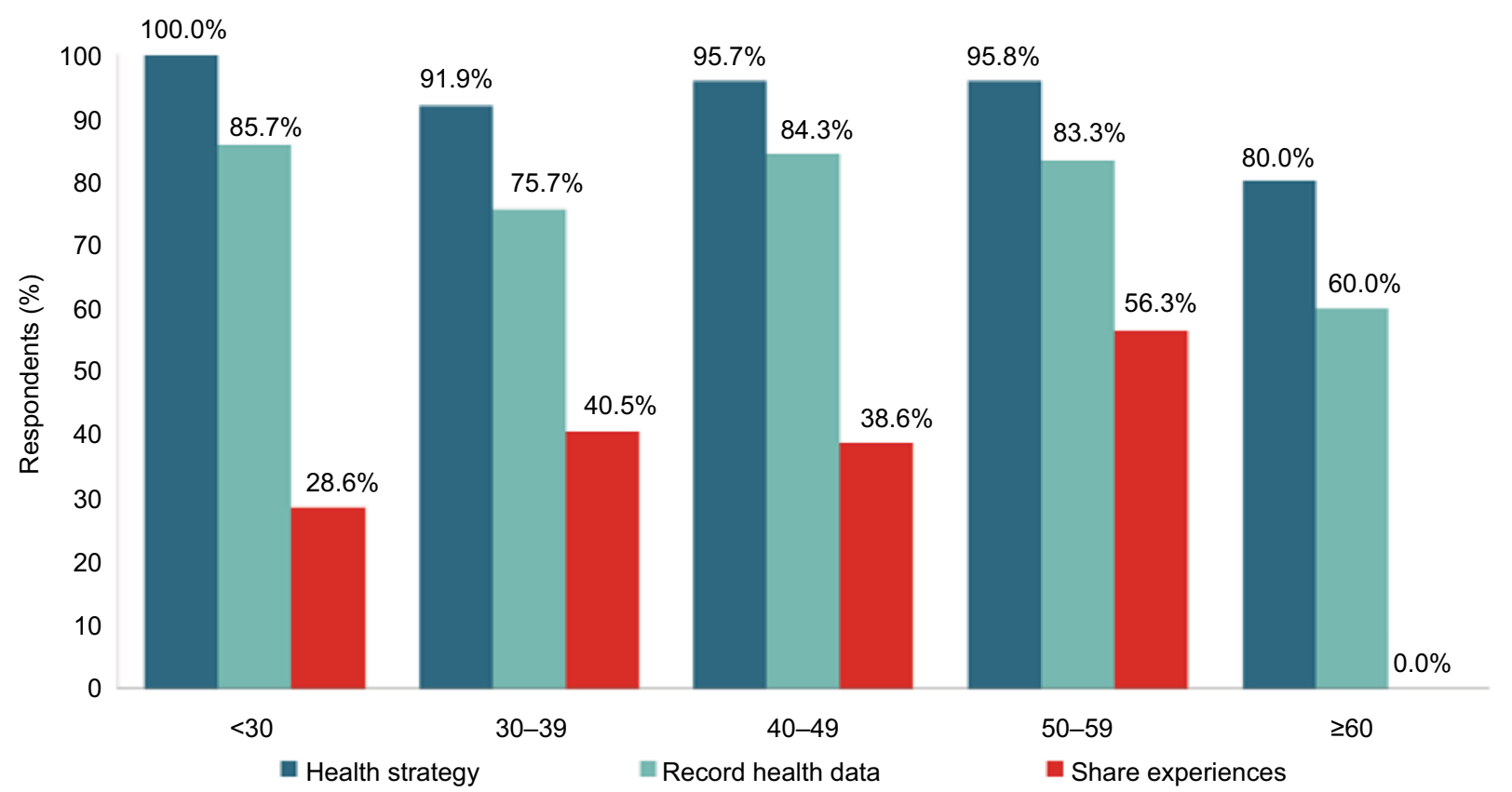

Figure 3 Range of ages versus three health strategies: any health strategy, record health data, and share experiences with other people.

with a partner, at least secondary education, and income between one and three times the minimum wage.

- Users have obesity and increased waist circumference.

- They access the Internet at least twice a week using a computer.

- More than $50 \%$ declare themselves as being physically active but not frequently practicing sports.

- They tend to feel stressed.

- They read digital media as well as print media, and more than half read topics related to health.

- The time of the day when they have more free time to take part in an ICT health intervention is before 8 am or after 6 pm (outside working hours).

\section{Specify user requirements}

The results of surveys, interviews, and focus group supported the definition of user requirements during the first two iterations of the system development. During the construction phase, user requirements were formalized.

The use case model presented in Figure 4 represents the activities that a user must perform with the system. The diagram represents the following PHR-S main functionalities: recording and viewing the five MS risk factors, sharing these measures with health care professionals, and the educational module on nutrition, stress management, and a physical activity.

\section{Produce design solutions to meet user requirements}

\section{First iteration}

The first prototype emerged during the elaboration phase of the software development process. The aim of this prototype (low-fidelity prototype) was to provide an initial description of the system. The development included the design of 


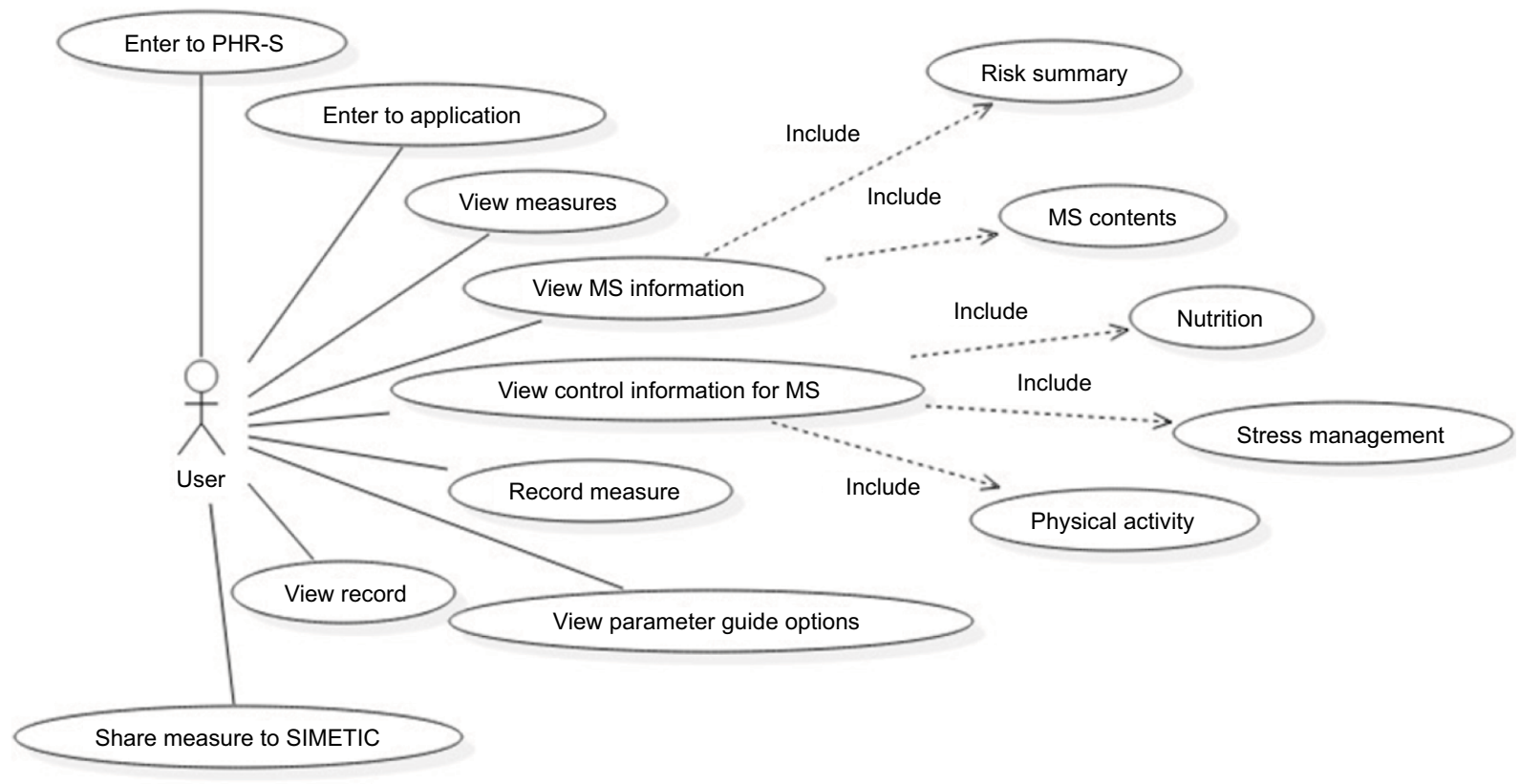

Figure 4 Use case model for the system.

Abbreviations: MS, metabolic syndrome; PHR-S, personal health record system.

navigable wireframes using Balsamiq and Marvel App tools. Examples of the prototype are shown in Figures 5 and 6.

\section{Second iteration}

The second prototype (high-fidelity prototype) was developed during the first iteration of the construction phase. Here, the system functionalities were implemented in the Indivo platform, ${ }^{28}$ and the user interfaces were professionally designed by a graphical designer. Indivo is a web platform that allows the collection, maintenance, and control of medical information directly by the patient; it is built with open standards and available under an open-source license. It is developed in Python under the web framework Django. Examples of the second prototype are shown in Figures 7 and 8.

\section{Third iteration}

The third and final prototype emerged during the second iteration of the construction phase. At this point, the remaining and newly elicited functionalities were implemented. In addition, design changes were made as a result of the previous usability tests. For example, participants encountered difficulties in locating information about MS control and navigating between the parameters of MS. This prototype was entirely designed by the graphic designer with the support of the development team. Examples of the final design of the system are presented in Figures 9 and 10.

\section{Evaluate the designs against requirements Evaluation of the first design prototype}

The evaluation of the first prototype (wireframes) was oriented to assess the initial design, the location of the elements, and the navigation of the application. The usability test had four tasks which were previously explained to the users as a text guide. Since it was a low-fidelity prototype, user satisfaction was not evaluated. Table 2 contains the results of the evaluation.

Since all participants completed the tasks, effectiveness was $100 \%$. However, in terms of efficiency, only four participants achieved the proposed goals. The only task that was completed by all participants within the specified time was the second one, and the tasks that took longer were tasks 1 and 3 (>10 s). Based on the results of the evaluation, the following changes were performed:

- Display explanations of normal values for each one of the MS parameters (eg, normal blood pressure is $<120 / 80 \mathrm{mmHg}$ );

- Use links instead of buttons;

- Insert help text in buttons to describe their functionality.

Also, some changes were proposed by team members:

- The project cannot afford a health professional available $24 \mathrm{~h}$ a day and 7 days a week, so online communication with a medical doctor was discarded.

- Exercise and nutrition recommendations were not personalized. 


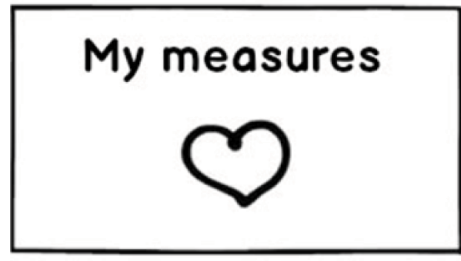

Nutrition

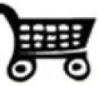

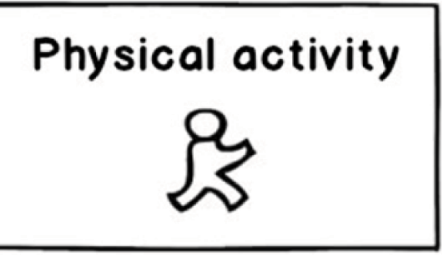

Stress management 因
Metabolic syndrome is a cluster of three or more factors of cardiovascular risk. These factors can be reversed if you take care of you nutrition, do physical activity, and manage stress

Your cardiovascular risk factors at this moment are:

* Increased waist circumference

* high glucose level

Your cardiovascular risk level is:

\section{MODERATE}

For more information go to My measures

Figure 5 First prototype of home page.

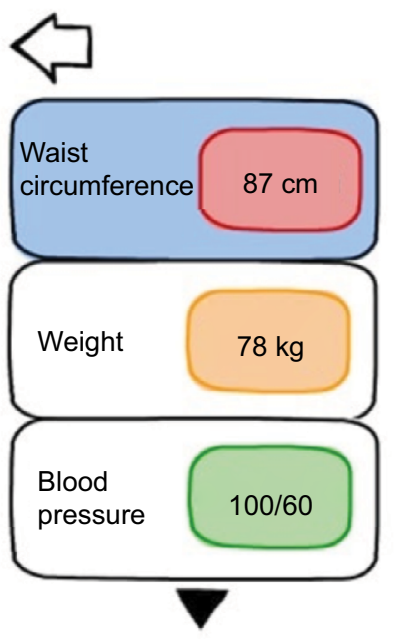

Your waist circumference

$$
87 \mathrm{~cm}
$$

Please be careful

Waist circumference in women should be less than $80 \mathrm{~cm}$

+ Add new measure
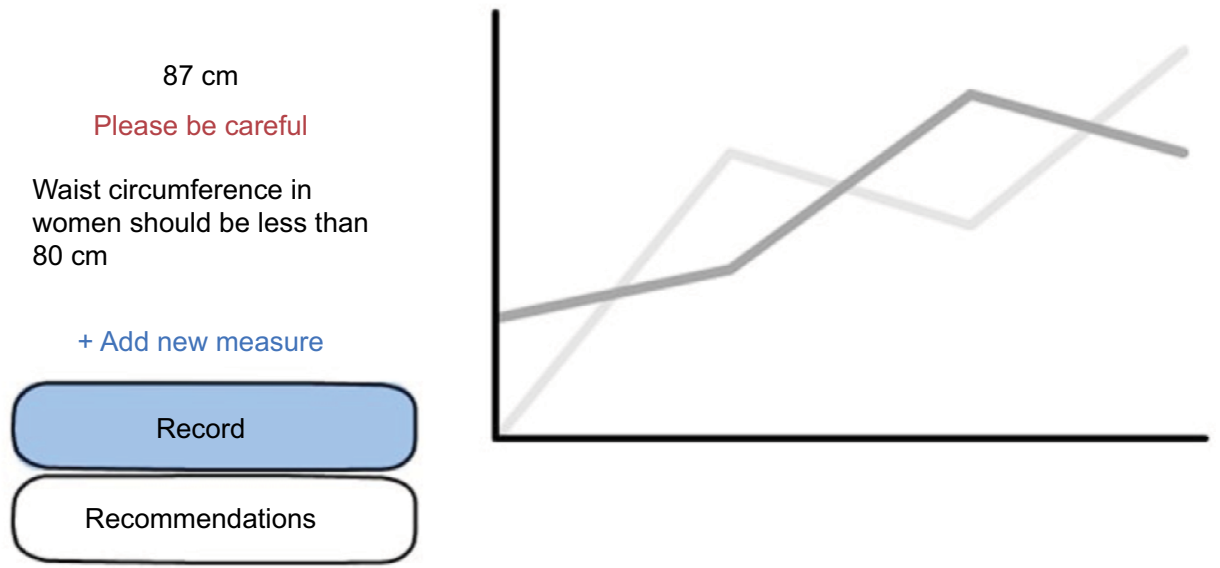

Figure 6 First prototype to record waist circumference page.

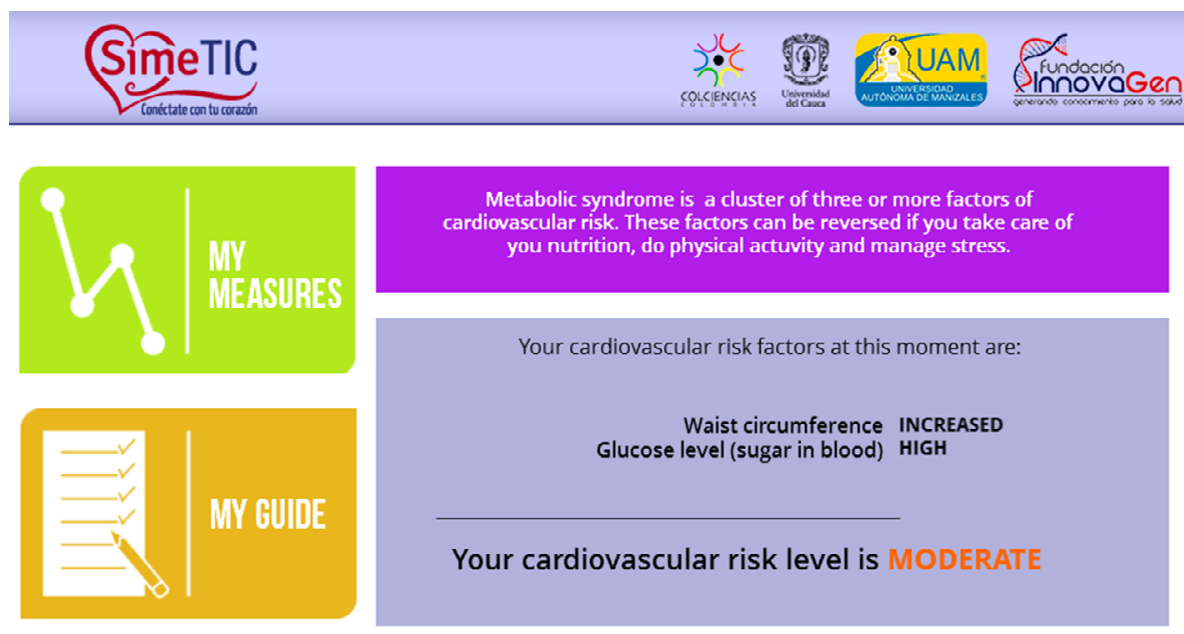

Figure 7 Second prototype of the home page. 


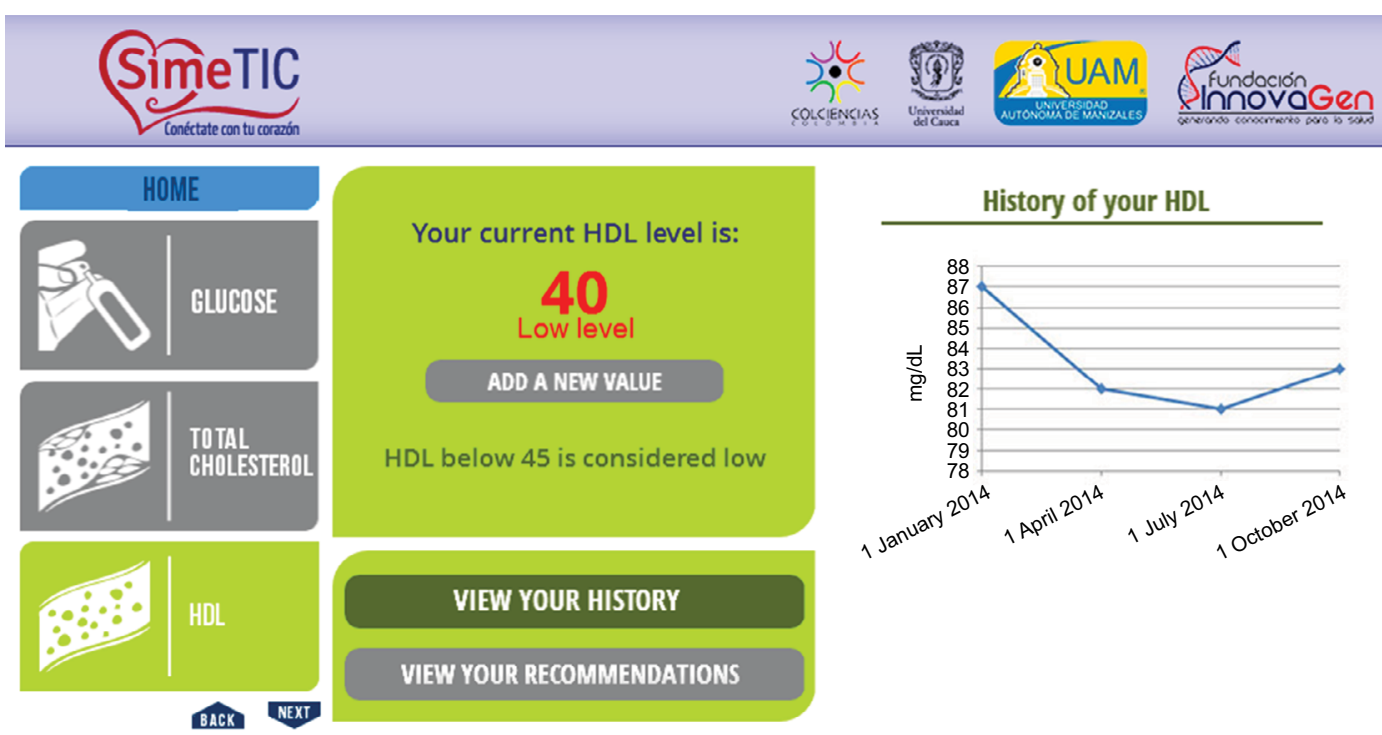

Figure 8: Second prototype of the high density lipoprotein (HDL) cholesterol-recording interface.

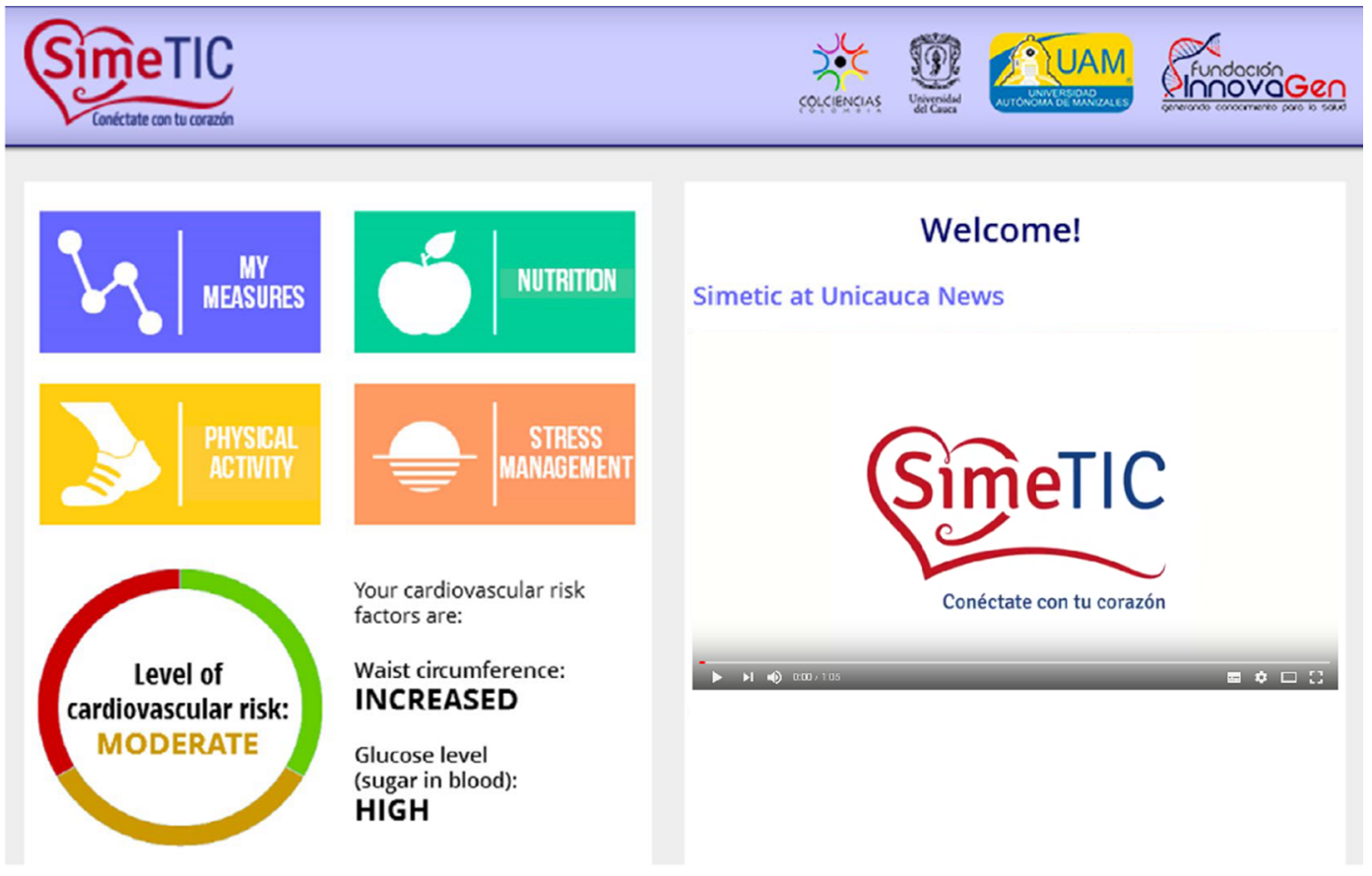

Figure 9 Final prototype of the home page.

- As the PHR-S is not interoperable with electronic medical records of patient's health care providers, users will not be able to share their PHR with their family doctors. Nevertheless, the information could be shared with private medical doctors belonging to the project, as long as the participants give authorization.

\section{Evaluation of the second design prototype}

The second prototype had much of the system already implemented in Indivo, which allowed the users to interact with a system that was closer to the final implementation. As it was consider a high-fidelity prototype, user satisfaction was assessed. Apart from the Think Aloud technique, users' opinions and other qualitative data were collected.

\section{Effectiveness}

Table 3 presents the results of the evaluation of system effectiveness. 


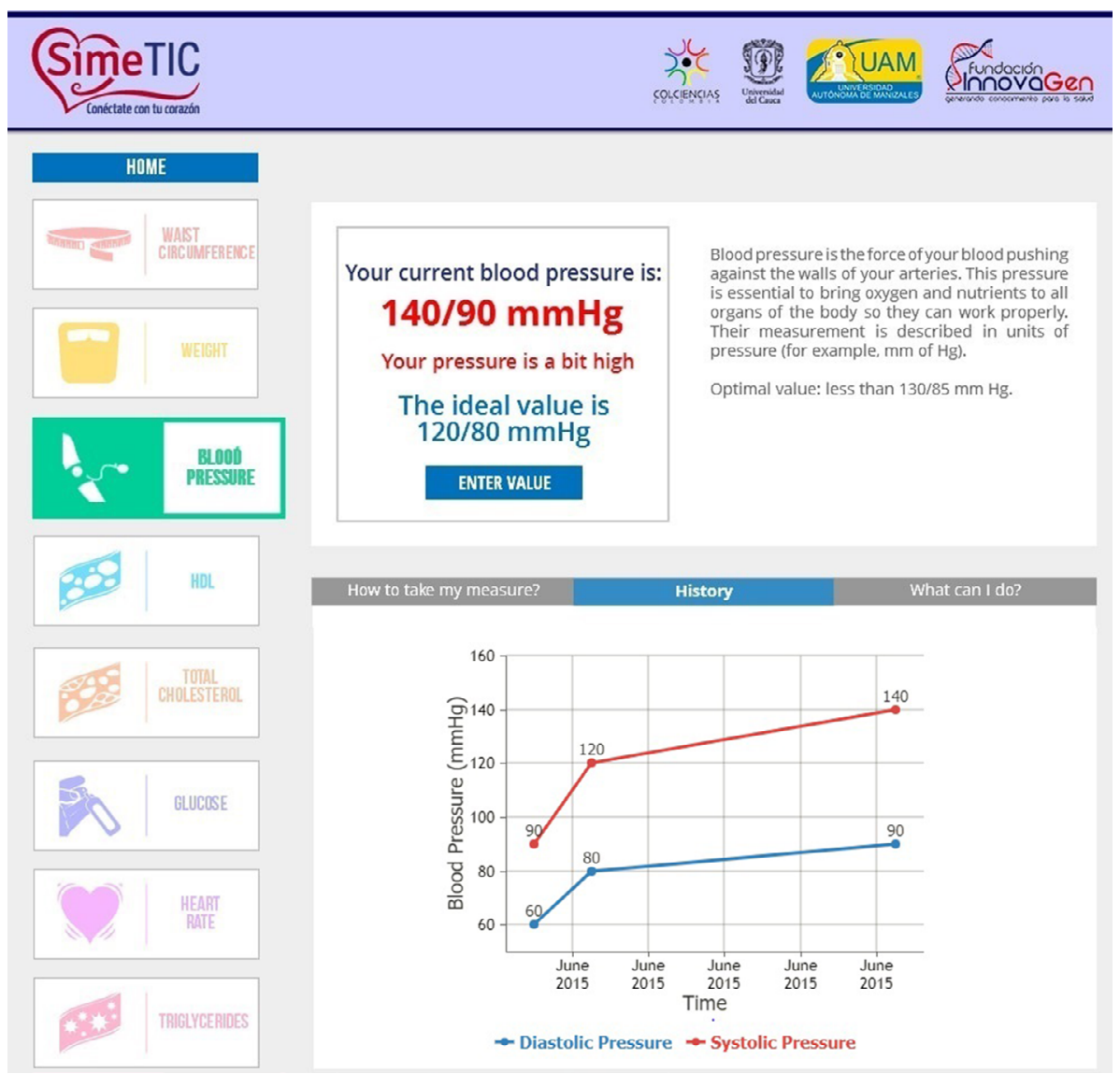

Figure 10 Final prototype of blood pressure-recording interface.

Table 2 Results of the efficiency evaluation for the first prototype

\begin{tabular}{llllllll}
\hline Task & \multicolumn{2}{l}{ User } & & & & & \\
\cline { 2 - 7 } & $\mathbf{I}$ & $\mathbf{2}$ & $\mathbf{3}$ & $\mathbf{4}$ & $\mathbf{5}$ & $\mathbf{6}$ & $\mathbf{7}$ \\
\hline $\mathrm{I}$ & $\checkmark$ & $\checkmark$ & $\checkmark$ & $\times$ & $\times$ & $\checkmark$ & $\checkmark$ \\
2 & $\checkmark$ & $\checkmark$ & $\checkmark$ & $\checkmark$ & $\checkmark$ & $\checkmark$ & $\checkmark$ \\
3 & $\checkmark$ & $\checkmark$ & $\checkmark$ & $\times$ & $\times$ & $\checkmark$ & $\times$ \\
4 & $\checkmark$ & $\checkmark$ & $\checkmark$ & $\checkmark$ & $\times$ & $\checkmark$ & $\checkmark$ \\
\hline
\end{tabular}

Notes: Tasks performed by users: I, record your weight; 2, view your record of blood pressure measurements; 3 , read the recommendations on glucose control; 4, visualize contents related to physical activity. There are two symbols to represent the accomplishment of the time goals: $\checkmark$, accomplished within the time target; $x$, not accomplished within the time target.

Tasks 1,3 , and 5 were successfully completed by 13 participants, achieving a $100 \%$ rate of success. Task 2 was completed by only $11(84.6 \%)$ participants, and task 4 was completed by only $10(76.9 \%)$ participants.

\section{Efficiency}

Table 4 presents the results of the evaluation of system efficiency. As the goal of task 2 was just to explore the application, the time spent in this task was not recorded; therefore, its efficiency could not be evaluated.
Table 3 Effectiveness evaluation for the second prototype

\begin{tabular}{llllll}
\hline Participant & Task I & Task 2 & Task 3 & Task 4 & Task 5 \\
\hline I & $\checkmark$ & $\checkmark$ & $\checkmark$ & $\checkmark$ & $\checkmark$ \\
2 & $\checkmark$ & $\times$ & $\checkmark$ & $\checkmark$ & $\checkmark$ \\
3 & $\checkmark$ & $\checkmark$ & $\checkmark$ & $\times$ & $\checkmark$ \\
4 & $\checkmark$ & $\times$ & $\checkmark$ & $\checkmark$ & $\checkmark$ \\
5 & $\checkmark$ & $\checkmark$ & $\checkmark$ & $\checkmark$ & $\checkmark$ \\
6 & $\checkmark$ & $\checkmark$ & $\checkmark$ & $\checkmark$ & $\checkmark$ \\
7 & $\checkmark$ & $\checkmark$ & $\checkmark$ & $\checkmark$ & $\checkmark$ \\
8 & $\checkmark$ & $\checkmark$ & $\checkmark$ & $\checkmark$ & $\checkmark$ \\
9 & $\checkmark$ & $\checkmark$ & $\checkmark$ & $\times$ & $\checkmark$ \\
10 & $\checkmark$ & $\checkmark$ & $\checkmark$ & $\times$ & $\checkmark$ \\
11 & $\checkmark$ & $\checkmark$ & $\checkmark$ & $\checkmark$ & $\checkmark$ \\
12 & $\checkmark$ & $\checkmark$ & $\checkmark$ & $\checkmark$ & $\checkmark$ \\
13 & $\checkmark$ & $\checkmark$ & $\checkmark$ & $\checkmark$ & $\checkmark$ \\
Successful tasks & 13 & $\mathrm{II}$ & 13 & 10 & 13 \\
$\%$ & 100 & 84.60 & 100 & 76.90 & 100 \\
\hline
\end{tabular}

Notes: Tasks performed by users: I, log into the PHR and enter to the application 2 , explore the application; 3 , add a new value in "my measures" section; 4 , view historical data and identify the section for reading, listening, and/or viewing medical recommendations; 5, identify the sections to read, listen, and/or view the content for stress management. The effectiveness evaluation evaluates whether a person can or cannot complete a task. Therefore, a tick mark means that the person could complete the task and a cross mark means that the person could not complete the task.

Efficiency was measured in terms of time required to execute a task. For example, the target time for task 3 was $60 \mathrm{~s}$, but the average execution time was $44.2 \mathrm{~s}$. 
Table 4 Efficiency evaluation for the second prototype

\begin{tabular}{|c|c|c|c|c|c|c|c|c|c|c|c|c|c|c|c|}
\hline \multirow[t]{2}{*}{ Participant } & \multicolumn{14}{|c|}{ Time per participant (s) } & \multirow[t]{2}{*}{ Target (s) } \\
\hline & $\mathbf{P I}$ & $\mathbf{P 2}$ & P3 & P4 & P5 & P6 & P7 & P8 & P9 & PIO & PII & $\mathbf{P} / 2$ & $\mathbf{P} \mid 3$ & Average & \\
\hline Task I & 37 & 62 & 25 & 36 & 42 & 51 & 27 & 47 & 33 & 28 & 39 & 108 & 43 & 44.5 & 40 \\
\hline Task 3 & 24 & 53 & 31 & 46 & 38 & 35 & 26 & 35 & 66 & 52 & 58 & 91 & 19 & 44.2 & 60 \\
\hline Task 4 & 18 & 69 & - & 117 & 76 & 140 & 7 & 16 & - & - & 92 & 97 & 41 & 67.3 & 60 \\
\hline Task 5 & II & 67 & 48 & 17 & 48 & 17 & 9 & 54 & 29 & 88 & 53 & 67 & 33 & 41.6 & 30 \\
\hline
\end{tabular}

Note: The "-" symbols indicate that the person could not complete the task; if the person did not complete the task, we could not measure the time.

Table $\mathbf{5}$ User satisfaction evaluation for the second prototype

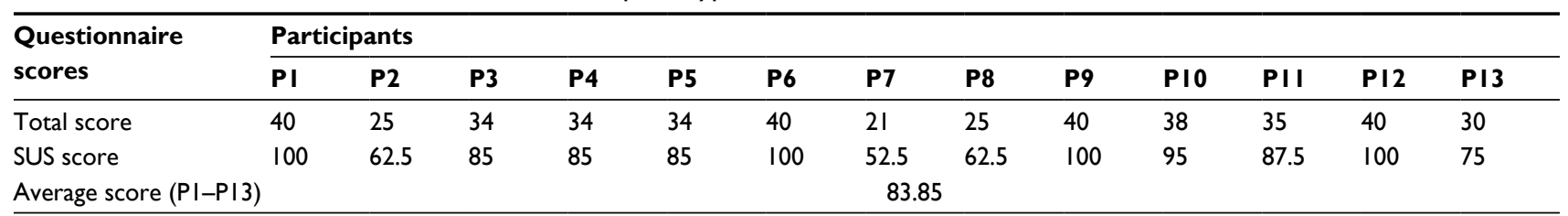

Abbreviation: SUS, system usability scale.

\section{User satisfaction}

Table 5 presents the results of the evaluation of user satisfaction by applying the SUS.

The average SUS score was 83.85. This result indicates a high acceptance because it exceeded the threshold of 80.3 proposed by Sauro, meaning that the result is above the mean of related usability studies. However, it is worth mentioning that three participants had scores: $62.5,52.5$, and 62.5. These values indicated low satisfaction and strongly influenced the overall average of the evaluation.

Changes in the design of prototype 2 after the quantitative and qualitative evaluations of the system were as follows:

- Change the type of navigation between MS parameters.

- Configure Indivo Chrome to show only the relevant functionalities for the project such as keeping the application enabled by defect.

- Ungroup the control information for MS to make these sections more evident.

- Integrate information to explain each parameter.

- Normalize the data entry.

Also, some changes were performed following the project's team requirements:

- It was necessary to integrate a physical activity plan to be delivered to users every month.

- Recommendations must include information about MS control.

\section{Evaluation of the last design prototype Effectiveness}

In terms of effectiveness, six participants achieved each of the tasks successfully, resulting in $100 \%$ completion of each task. This shows a marked improvement in task 4 that turned out to be the most criticized task in the previous assessment. Also, in accordance with the new design, the sixth task was added for this evaluation, which probed to be successful too.

\section{Efficiency}

Table 6 presents the results of the evaluation of efficiency in the third prototype.

The time to complete all the tasks was below the goal.

\section{User satisfaction}

Table 7 presents the results of the evaluation of user satisfaction.

The SUS provided a user acceptance value of 84.2, increasing the acceptance of the previous iteration (83.85 points). This result indicated high acceptance because it exceeded the threshold proposed by Sauro of 80.3. However, it is worth mentioning that there were two participants who obtained a score of 67.5 and 60 , respectively. These values indicated low satisfaction and strongly influenced the overall results of the evaluation. Analyzing also the qualitative data, the following changes were made:

- Add explanations to the MS parameters' graphs in order to make it more understandable.

- When a parameter option is clicked on, focus the screen in the space where the content of the option is going to be displayed.

- Add audio guides or videos explaining recommendations on physical activity.

\section{Discussion}

This paper describes the design and development process of a PHR-S for the management of MS, which was developed strictly following a software development process in 
Table 6 Efficiency evaluation for the third prototype

\begin{tabular}{|c|c|c|c|c|c|c|c|c|}
\hline \multirow[t]{2}{*}{ Task } & \multicolumn{6}{|c|}{ Time per participant (s) } & \multirow[t]{2}{*}{ Average per task (s) } & \multirow[t]{2}{*}{ Target (s) } \\
\hline & $\mathbf{P I}$ & P2 & P3 & P4 & P5 & P6 & & \\
\hline Task I & 56 & 34 & 21 & 34 & 33 & 32 & 35.0 & 40 \\
\hline Task 3 & 42 & 30 & 83 & 49 & 34 & 55 & 48.8 & 60 \\
\hline Task 4 & 29 & 33 & 170 & 51 & 33 & 84 & 75.2 & 80 \\
\hline Task 5 & 13 & 52 & 18 & 14 & 12 & 18 & 21.2 & 30 \\
\hline Task 6 & $\mathrm{II}$ & 24 & 28 & 17 & 18 & 21 & 19.8 & 30 \\
\hline Average & 42.0 & 35.8 & 99.3 & 32.8 & 40.3 & 76.3 & 54.4 & Not applicable \\
\hline
\end{tabular}

Table 7 User satisfaction evaluation for the third prototype

\begin{tabular}{lllllll}
\hline Questionnaire & \multicolumn{7}{l}{ Participants } \\
\cline { 2 - 7 } scores & PI & P2 & P3 & P4 & P5 & P6 \\
\hline Total score & 40 & 38 & 39 & 27 & 34 & 24 \\
SUS score & 100 & 95 & 97.5 & 67.5 & 85 & 60 \\
Average score (PI-P6) & & \multicolumn{7}{c}{84.2} & & \\
\hline
\end{tabular}

Abbreviation: SUS, system usability scale.

accordance with the ISO 9241-210 international specification on human-centered design for interactive systems. The study showed how the requirements and recommendations of the ISO 9241-210 specification were integrated within a traditional development process such as the OpenUP/MMUISO software process, which has been derived from the rational unified process. As required by UCD, this study was performed in a multidisciplinary environment, supported by user data collection techniques such as surveys, interviews, and a focus group. In addition, the process had a permanent focus on users, who played an active role contributing to the system design from the first iteration in the inception phase until the last iteration in the construction phase. Furthermore, the development process used an iterative method from where three prototypes of the system were constructed. Following recommendations of the ISO/IEC 25022 (SQUARE) specification, these prototypes were assessed by potential users of the system through usability testing. The usability characteristics analyzed were effectiveness, efficiency, and user satisfaction.

Based on a review of related work, it was concluded that there is no PHR-S developed exclusively for the management of MS and that existing ones are oriented to related health conditions such as diabetes or promotion of healthy habits and lifestyles. Moreover, none of the existing PHR-Ss have been developed taking into consideration the ISO 9241-210 standard. Therefore, this study is considered as a reference for future projects in which the design and development of PHR-Ss, following standard-based, human-centered software development methodologies, is demanded. In addition, the establishment of a multidisciplinary team provided the application with considerations not only from the disciplines of software engineering and health sciences but also from other disciplines such as graphical design and media communication. This proves the value of interdisciplinarity for improving the quality and effectiveness of eHealth. Moreover, it showed in practice a synergy and constructive dialog between health services' research and software development, a current challenge in eHealth clearly described by Plagiary. ${ }^{29}$

Examples of the most relevant related work includes the work of Massoudi et al, ${ }^{30}$ which develops a personal health application (PHA) to support a lifestyle intervention based on behavioral change, through a highly individualized physical activity plan. The design of the PHA was based on the UCD, for which several focus groups and structured interviews with 28 users (sedentary adults with and without chronic diseases), eight health professionals (doctors, nurses, and physiotherapists), and six personal trainers were conducted. It held a single product iteration, where account creation, use of the PHA to record and review the physical activity, and integration of components were evaluated. Cafazzo et al ${ }^{31}$ describe the design and development of a pilot mHealth intervention for the management of type 1 diabetes in adolescents. Design decisions are described in detail (produce design solutions phase). UCD was supported by qualitative, ethnographic interviews with children and caregivers and a focus group with clinical experts. User satisfaction was measured. Harris et al ${ }^{32}$ performed the evaluation of a prototype application for mobile phones, designed to help diabetes patients understand daily trends in their glucose levels through graphics displayed on their phone and on a web page, as well as provide communication with health care providers. System evaluation was conducted in two phases. The first consisted of a group of six people with type 1 or 2 diabetes, aged 18-65 years; they evaluated the wireless transfer of data from a glucometer and the automatic dispatch of SMS. The second evaluation was conducted for eight people with type 2 diabetes aged between 18 and 70 years and sought to evaluate the full use of the application. The results led to changes in the prototype. Fonda et $\mathrm{al}^{33}$ developed a prototype of a PHA and described the changes made to it, in response to user feedback. The requirements of the prototype were gathered through series 
of three focal groups with diabetes patients. However, the system design, requirements, and users' feedback were not described in detail. There are examples of PHR developed in other health areas where UCD aspects are considered, eg, cancer patients, ${ }^{34}$ medication management,${ }^{35}$ sleep apnea, ${ }^{36}$ treatment plans, ${ }^{37}$ pain management, ${ }^{38}$ medications management, ${ }^{39}$ and other health problems. Recently, a guide for developing Internet-based health interventions has been published, which uses the User-Centered Design Process Map from the US Department of Health and Human Services as methodology to interview experts, in order to provide recommendations for the development of online health interventions. ${ }^{40}$ However, gaps were found in the aforementioned related works: 1) the projects have not been implemented according to recommendations and requirements of the international standard ISO 9241-210 for human-centered development of interactive systems; 2) they do not mention the use of a software methodology to integrate the UCD into its life cycle; and 3) in some of them, the participation of multidisciplinary teams in the design was not reported.

The PHR-S reported in this paper was developed using the OpenUP/MMU-ISO 9241-210 software development process, which integrates to its phases of development (inception, elaboration, construction, and transition), the four main UCD activities specified in the ISO 9241-210 standard. The first UCD phase was to understand and specify the context of use. From the survey conducted, it was identified that the prevalence of MS was $39.4 \%$. This was a rather high value in the study population in Cauca, Colombia, since it is estimated that by $2020,28 \%$ of men and $58.7 \%$ of women will have abdominal obesity. ${ }^{41}$ The PHR-S proposed intends to provide ICT alternatives for MS control, given that $75.2 \%$ of the people with MS use the Internet frequently. In particular, the PHR had an acceptance rate of $67.9 \%$ among the sampled individuals. In this phase, two more techniques for data collection were used: interviews and focus groups. Although these activities took time and effort and relied on the user's availability, they allowed collecting enough baseline data to understand the potential users of the system, as well as being a key input in the following UCD activity. However, it is necessary to take into account that, due to the complexity and diversity of human nature, fully understanding each person and describing their interaction with computer systems become challenging.

The second and third UCD phases were specify the user requirements and produce design solutions. These traditional activities in any software development process were complemented with human-centered approaches. The new tasks and activities provided by the ISO 9241-210 standards allowed taking into account the views and considerations of the user throughout the project. Therefore, it increased the chance of having high satisfaction and high acceptance. It also allowed members of the development team to keep a focus on the requirements and needs of the users. Moreover, it facilitated the continuous evaluation of the developed models and artifacts in the system's context of use. Compared to other software engineering projects that use traditional methods without UCD, it could be concluded that the UCD activities increased the complexity of the development process, in terms of time and documentation. However, the product quality was higher, especially satisfaction and user acceptance as shown in usability evaluation.

Regarding the UCD phase, evaluate the designs against requirements, it was demonstrated how the active participation of the user in the system's evaluation helped to reach a highquality software system. Effectiveness and efficiency were evaluated in the first prototype (elaboration phase). Effectiveness was $100 \%$, indicating a total accomplishment of the tasks; efficiency did not meet expectations in three of the four tasks set. In the second prototype (construction phase), user satisfaction was also measured; also, qualitative data on users' interaction were collected by reviewing their actions and observations (provided by the Think Aloud technique). Effectiveness was $92.3 \%$, and efficiency was very low, as only one goal was fulfilled of the four evaluated. In addition, the SUS score was 83.85 , which is a very positive value. The lower results obtained in this prototype were attributed to several factors; first, it should be considered that this was the first functional prototype, so there were new secondary functionalities that could distract users from their goal. Second, this prototype was implemented in Indivo, which comes with its own interface and functionalities. In consequence, it added factors that complicated user's performance in the test. Third, the navigation inside the PHR proved to be confusing for the users; for example, $23.1 \%$ of the users could not find the specified MS parameter during the test. Finally, some of the information architecture defined in the prototype was not completely understood by the users; for example, some users could not identify information on MS control. The $23.1 \%$ refers to three people from a group of 13 people, who could not complete the task in prototype 2 . In prototype 3, everyone could complete the task, which justifies the increase in the total SUS measure.

In the final usability test conducted in the third prototype (second iteration of the construction phase), effectiveness was $100 \%$, indicating that errors present in the previous prototype were corrected. Efficiency was $100 \%$, given that all the objectives were met. In particular, the evaluations made showed that user satisfaction increased, as the solution was refined, 
presumably because user recommendations were addressed, obtaining a final SUS score of 84.2. In addition, the metrics of effectiveness and efficiency reached the highest success rate in the final prototype of the solution.

Despite significant results in terms of user satisfaction, in iteration 2, participants 2, 7, and 8 obtained poor results. Examining their individual results for efficiency and effectiveness, it is possible to conclude that the worst performance belongs to participant 2, who did not complete one task (effectiveness) and had three of the four tasks outside the established time goal (efficiency). On the contrary, participant 8 had two of the four tasks outside the established time goal, and participant 7 had very good results in both efficiency and effectiveness. Thus, a possible justification for the low user satisfaction provided by participants 2 and 8 could be their inability to complete some tasks. Participant 7 had very good results in both efficiency and effectiveness but poor results in SUS. His/her poor result may have been due to the influence of the visual design, a lack of interest, or even the emotional state in which he/she was at the time. At iteration 3, participants 4 and 6 had low satisfaction scores; however, in this case, they also had high scores in efficiency and effectiveness, where only participant 6 exceeded one of the time goals. Therefore, although the participants completed the tasks and accomplished them in time, they were not entirely pleasant with the conducted test.

An important observation resulting from the usability tests was that some participants did not understand the questions from the SUS questionnaire. Thus, a review of the SUS is necessary in order to make its questions easier to understand, at least in Spanish language. Also, there are different ways to run a usability test; in this study, they were conducted at the workplace, and the computer screen and the user's face were recorded for further analysis. It is considered that the execution of these tests in an appropriate usability laboratory could facilitate the analysis, thereby obtaining more accurate results.

As a future work, it is proposed to evaluate the system's performance over a period of at least 12 months; this might allow obtaining new considerations that can improve the system's design. This evaluation will be part of a larger RCT, which is currently under development. ${ }^{41}$ It is also planned to add functionalities to the PHR-S, based on requirements elicited by RCT participants. Also, the RCT requires that the systems deploy an administration interface for the system's administrator to handle the system more easily and have a mechanism to contact a medical doctor if necessary. For the users, it could be necessary to have a space for writing suggestions or the ability to export or print the measures recorded in the PHR. It is also considered important to evolve the PHR-S toward a personalized health system, eg, considering contextual information and using sensors, such as accelerometers. It could provide personalized physical activity recommendations. Finally, from the software engineering point of view, a still-unexplored path is to integrate the ISO 9241-210 principles and recommendations to agile development process, such as the Scrum methodology.

\section{Conclusion}

This paper provides a detailed description of the analysis, design, implementation, and evaluation stages of a PHR-S for the management of MS. The system was developed following a software development process in accordance with the ISO 9241-210 international specification on human-centered design for interactive systems. The literature review allowed to conclude that there are no PHR-Ss developed based on the ISO 9241-210 international standard, and none of existing PHR-Ss found are specifically oriented to MS. Using the OpenUP/MMU-ISO 9241-210 process into the development of the MS PHR-S allowed the software development team to maintain a focus on the requirements and user's needs. The above increased user satisfaction and acceptance of the system. In particular, user satisfaction increased as the solution was refined, reaching a final SUS score of 84.2 points, which reflects high user acceptance. The final efficiency and effectiveness of the system was $100 \%$.

\section{Acknowledgment}

The work has been funded by the Colombian Administrative Department of Science and Technology in Colombia (Colciencias) - Call 569-2012 under the project SIMETIC: Una estrategia para la caracterización y autocuidado de pacientes con Síndrome Metabólico soportada en Tecnologías de la Información y la Comunicación (TIC), under contract number 110356935192/CTO: 743-2013.

\section{Disclosure}

The authors report no conflicts of interest in this work.

\section{References}

1. World Health Organization. Global Status Report on Noncommunicable Diseases. 2010. Available from: http://www.who.int/nmh/publications/ ncd_report_full_en.pdf. Accessed July 21, 2015.

2. World Health Organization in Collaboration with the World Heart Federation and the World Stroke Organization. Global Status Report on Noncommunicable Diseases. 2014. Available from: http://apps. who. int/iris/bitstream/10665/148114/1/9789241564854_eng.pdf?ua $=1$. Accessed September 9, 2015.

3. Colin DM, Loncar D. Projections of global mortality and burden of disease from 2002 to 2030. PLoS Med. 2006;3(11):2011-2030.

4. George A, Zimmet P, Shaw J, Grundy SM. The IDF Consensus Worldwide Definition of the Metabolic Syndrome. 2006. Available from: https:// www.idf.org/e-library/consensus-statements/60-idfconsensus-worldwidedefinitionof-the-metabolic-syndrome.html. Accessed December 11, 2017. 
5. Zimmet P, Alberti KGMM, Ríos MS. Una nueva definición mundial del síndrome metabólico propuesta por la Federación Internacional de Diabetes: fundamento y resultado. [A new worldwide definition of the metabolic syndrome proposed by the International Diabetes Federation: rationale and result] Rev Esp Cardiol. 2005;58(12):1371-1376. Spanish.

6. Wilson PW, D'Agostino RB, Parise H, Sullivan L, Meigs JB. Metabolic syndrome as a precursor of cardiovascular disease and type 2 diabetes mellitus. Circulation. 2005;112(20):3066-3072.

7. Mokdad AH, Ford ES, Bowman BA, et al. Prevalence of obesity, diabetes, and obesity-related health risk factors, 2001. JAMA. 2003;298(1):76-79.

8. Ford ES, Giles WH, Mokdad AH. Increasing prevalence of the metabolic syndrome among U.S. adults. Diabetes Care. 2004;27(10):2444-2449.

9. Fjeldsoe BS, Marshall AL, Miller YD. Behavior change interventions delivered by mobile telephone short-message service. Am J Prev Med. 2009;36(2):165-173.

10. Park M-J, Kim H-S. Evaluation of mobile phone and Internet intervention on waist circumference and blood pressure in post-menopausal women with abdominal obesity. Int J Med Inform. 2012;81(6):388-394.

11. Chen YC, Tsao LI, Huang CH, Yu YY, Liu IL, Jou HJ. An Internet-based health management platform may effectively reduce the risk factors of metabolic syndrome among career women. Taiwan J Obstet Gynecol. 2013;52(2):215-221.

12. Youma S, Leeb G, Parkb S, Zhua W. Development of remote healthcare system for measuring and promoting healthy lifestyle. Expert Syst Appl. 2011;38(3):2828-2834.

13. Brennan PF, Downs S, Casper G. Project HealthDesign: rethinking the power and potential of personal health records. $J$ Biomed Inform. 2010;43(5):S3-S5.

14. Huba N, Zhang Y. Designing patient-centered personal health records (PHRs): health care professional's perspective on patient-generated data. J Med Syst. 2012;36(6):3893-3905.

15. ISO/TR 14292 Draft. Personal Health Records - Definition, Scope and Context. Vol ISO TC 215/SC; 2011.

16. Brennan PF, Casper GR, Downs S, Aulahk V. Project HealthDesign: enhancing action through information. Stud Health Technol Inform. 2009;146:214-218

17. Waljia MF, Kalenderian E, Piotrowski M. Are three methods better than one? A comparative assessment of usability evaluation methods in an HER. Comp Assess Usability Eval Methods HER Int J Med Inform. 2014;83(5):361-367.

18. ISO 9241-210:2010. Ergonomics of Human-System Interaction-Part 210: Human-Centred Design for Interactive Systems. 2015. Available from: http://www.iso.org/iso/home/store/catalogue_ics/catalogue_detail_ics. htm?csnumber=52075. Accessed March 18, 2015.

19. Hassan Y, Martín F, Iazza G. Diseño Web Centrado en el Usuario: Usabilidad y Arquitectura de la Información [User-centered web design: usability and information architecture]. Available from: https://www. upf.edu/hipertextnet/numero-2/diseno_web.html. Accessed March 18, 2015. Spanish.

20. Cerón JD, et al. Estrategias basadas en tecnologías de la información y la comunicación para la reducción de factores de riesgo cardiovascular en personas laboralmente activas [Strategies based on information and communication technologies for the reduction of cardiovascular risk in occupationally active people]. Rev Colomb Cardiol. In press 2017. Spanish.

21. Rodriguez A. OpenUP/MMU-ISO Soporte para un proceso de desarrollo de Software conforme al Modelo ISO de Madurez en Usabilidad [Support for a process of Software development in accordance with the ISO model of usability maturity]. 2010. Available from: https://www.researchgate. net/publication/304041625_OpenUPMMU-ISO_Soporte_para_un_proceso_de_desarrollo_de_software_conforme_al_Modelo_ISO_de_Madurez_en_Usabilidad. Accessed December 14, 2014. Spanish.

22. Farinango CD, Benavides JS, Lopez DM. OpenUP/MMU-ISO 9241210. Process for the human centered development of software solutions. IEEE Lat Am Trans. 2015;13(11):3668-3675.
23. Farinango CD, Benavides JS. Dissertation: Un Sistema de Registros de Salud Personal para Síndrome Metabólico, desarrollado conforme a requisitos y recomendaciones de la especificación ISO 9241-210 [A personal health records system for metabolic syndrome, developed in accordance with recommendations of the ISO 9241-210 specification and requirements]. Popayán, Colombia: Facultad de Ingenieria Electronica y Telecomunicaciones, Universidad del Cauca; 2015. Spanish.

24. Heart360 [homepage on the Internet]. Welcome. 2015. Available from: https://www.heart360.org/. Accessed July 27, 2015.

25. ISO/IEC DIS 25022. Systems and Software Engineering - Systems and Software Quality Requirements and Evaluation (SQuaRE) - Measurement of Quality in Use. 2012. Available from: https://www.iso.org/ standard/35746.html. Accessed December 14, 2014.

26. U.S. Department of Health \& Human Services. Home, Usability.gov. 2015. Available from: http://www.usability.gov/. Accessed July 26, 2015.

27. U.S. Department of Health \& Human Services [webpage on the Internet]. System Usability Scale (SUS), Usability.gov. 2015. Available from: http://www.usability.gov/how-to-and-tools/methods/system-usabilityscale.html. Accessed July 26, 2015.

28. Indivohealth [homepage on the Internet]. The Indivo Personally Controlled Health Record. 2015. Available from: http://indivohealth.org/. Accessed November 6, 2015.

29. Pagliari C. Design and evaluation in eHealth: challenges and implications for an interdisciplinary field. J Med Internet Res. 2007;9(2):e15.

30. Massoudi BL, Olmsted MG, Zhang Y, Carpenter RA, Barlow CE, Huber R. A web-based intervention to support increased physical activity among at-risk adults. J Biomed Inform. 2010;43(5 suppl):S41-S45.

31. Cafazzo JA, Casselman M, Hamming N, Katzman DK, Palmert MR. Design of an mHealth app for the self-management of adolescent type 1 diabetes: a pilot study. J Med Internet Res. 2012;14(3):e70.

32. Harris LT, Tufano J, Le T, et al. Designing mobile support for glycemic control in patients with diabetes. J Biomed Inform. 2010;43(5 suppl):S37-S40.

33. Fonda SJ, Kedziora RJ, Vigersky RA, Bursell S-E. Evolution of a web-based, prototype personal health application for diabetes selfmanagement. J Biomed Inform. 2010;43(5 suppl):S17-S21.

34. Urda D, Ribelles N, Subirats JL, Franco L, Alba E, Jerez JM. Addressing critical issues in the development of an oncology information system. Int J Med Inform. 2013;82(5):398-407.

35. Slagle JM, Gordon JS, Harris CE, et al. MyMediHealth - designing a next generation system for child-centered medication management. $J$ Biomed Inform. 2010;43(5 suppl):S27-S31.

36. Proceedings of the 2013 Industrial and Systems Engineering Research Conference. Institute for Industrial Engineers (IIE) Annual Conference and Expo, San Juan, Puerto Rico. Available from: https://www.researchgate. net/publication/265291896_VisOSA_Visualizing_Obstructive_Sleep_ Apnea_Symptoms_and_Comorbidities. Accessed March 18, 2015.

37. Luckmann R, Vidal A. Design of a handheld electronic pain, treatment and activity diary. $J$ Biomed Inform. 2010;43(5 suppl):S32-S36.

38. Klasnja P, Hartzler A, Powell C, Phan G, Pratt W. Health weaver mobile: designing a mobile tool for managing personal health information during cancer care. AMIA Annu Symp Proc. 2010;2010:392-396.

39. Ross SE, Johnson KB, Siek KA, Gordon JS, Khan DU, Haverhals LM. Two complementary personal medication management applications developed on a common platform: case report. J Med Internet Res. 2011;13(3):e45.

40. Horvath KJ, Ecklund AM, Hunt SL, Nelson TF, Toomey TL. Developing internet-based health interventions: a guide for public health researchers and practitioners. $J$ Med Internet Res. 2015;17(1):e28.

41. Alvarez RE, Sierra-Torres CE, Benitez S, Lopez DM. SIMETIC: Una estrategia para la caracterizacion y autocuidado de pacientes con sindrome metabolico soportada en Tecnologias de la Informacion y la Comunicacion (TIC), 2012, Grant Proposal. ID: Convocatoria $569-$ 2012 Banco de proyectos elegibles de CTel [SIMETIC: a strategy for the characterization and self-care of patients with metabolic syndrome supported in information technology and communication (ICT), 2012, Grant Proposal. ID: Call 569-2012 CTel eligible project Bank]. Spanish 


\section{Publish your work in this journal}

The Journal of Multidisciplinary Healthcare is an international, peerreviewed open-access journal that aims to represent and publish research in healthcare areas delivered by practitioners of different disciplines. This includes studies and reviews conducted by multidisciplinary teams as well as research which evaluates the results or conduct of such teams or health care processes in general. The journal covers a very wide range of areas and welcomes submissions from practitioners at all levels, from all over the world. The manuscript management system is completely online and includes a very quick and fair peer-review system. Visit http://www.dovepress.com/ testimonials.php to read real quotes from published authors.

Submit your manuscript here: https://www.dovepress.com/journal-of-multidisciplinary-healthcare-journal 